\title{
A Controlled Study of Neuropsychological Deficits in Acute Spinal Cord Injury Patients
}

\author{
E. Roth, MD, ${ }^{1,2}$ G. Davidoff, MD, MS, ${ }^{3,4}$ P. Thomas, PhD, ${ }^{5}$ R. Doljanac, \\ MA, ${ }^{3}$ M. Dijkers, PhD, ${ }^{5}$ S. Berent, PhD, ${ }^{6}$ J. Morris, PhD, ${ }^{1,7}$ G. Yarkony, \\ $\mathrm{MD}^{1,2}$ \\ ${ }^{1}$ Midwest Regional Spinal Cord Injury Care System, Departments of ${ }^{2}$ Rehabilita- \\ tion Medicine and ${ }^{7}$ Psychiatry and Behavioral Sciences, Northwestern University \\ Medical School, Chicago, IL and the Rehabilitation Institute of Chicago, IL, \\ USA, Departments of ${ }^{3}$ Physical Medicine and Rehabilitation and ${ }^{6}$ Psychiatry, \\ University of Michigan Medical Center, Ann Arbor, MI, USA, ${ }^{4}$ Rehabilitation \\ Medicine Service, Veterans Administration Medical Center, Ann Arbor, MI, \\ USA, ${ }^{5}$ South Eastern Michigan Spinal Cord Injury System, Rehabilitation Insti- \\ tute, Detroit, MI, USA.
}

\section{Summary}

According to a number of studies, between $40^{\circ}$; and $60 \%$ of acute traumatic spinal cord injury ( $S C I$ ) patients demonstrate cognitive dysfunction resulting from various forms of cerebral damage, including concurrent or premorbid closed head injury, chronic alcohol or substance abuse, and other causes. However, applicability of findings from these reports has been limited due to the use of inadequate neuropsychological testing techniques and the lack of control data. In a collaborative investigation, 81 acute SCI patients and 61 non-injured control subjects between 18 and 55 years of age completed a comprehensive motor-free neuropsychological test battery, including: Halstead Category Test (HCT), Vocabulary Subtest (VOCAB) of the Wechsler Adult Intelligence Scale - Revised; Mental Control (MC) Subtest, and Initial and Recall trials of Logical Memory (LM) and Paired Associates (PA) Subtests of the Wechsler Memory Scale; and the 8 trials of the Rey Auditory Verbal Learning Test (RAVLT). Percentages of retained information on the LM and PA were also calculated. Impairment levels for each test were defined as values which exceeded two standard deviations (one-tailed) from the control mean. Based on this definition, the prevalence of neuropsychological abnormality on each test ranged between $10 \%$ and $40 \%$. Mean performance levels of patients were significantly more impaired than those of control subjects for all tests

Correspondence to: Elliot Roth, MD, Rehabilitation Institute of Chicago, 345 E. Superior Street, Chicago, IL 60611, USA.

Presented in part at the 64th Annual Session of the American Congress of Rehabilitation Medicine, Orlando, FL, 21 October 1987, and at the Fourteenth Annual Scientific Meeting of the American Spinal Injury Association, San Diego, CA, 2-4 May 1988. 
except for the Interference trial of the RAVLT and for the percentages of retained information on the LM and PA subtests. Comparison of test results of SCI patients with those of control subjects demonstrates that poor attention span and limited initial learning ability are frequent problems among SCI patients. Other common neuropsychological deficits among these patients include poor concentration ability, impaired memory function, and altered problem solving ability. These deficits may interfere with rehabilitation following SCI.

Key words: Spinal cord injury; Neuropsychological deficits; Closed head injury; Rehabilitation.

Between $40 \%$ and $60 \%$ of patients with acute spinal cord injury (SCI) demonstrate various types of cognitive deficits (Schueneman and Morris, 1982; Davidoff et al., 1985a; Wilmot et al., 1985; Morris et al., 1986; Davidoff et al., 1987; Richards et al., 1988). These disorders may include poor attention and concentration, disturbed memory and learning, impaired visuospatial perception, and decreased problem-solving ability, all of which present barriers to full and optimal rehabilitation after spinal cord trauma.

Factors which may contribute to the occurrence of cognitive dysfunction among patients with traumatic myelopathy include concurrent or premorbid traumatic brain injury (Silver et al., 1980-81; Schueneman and Morris, 1982; Dubo and Delaney, 1984; Wagner et al., 1984; Davidoff et al., 1985a; Wilmot et al., 1985; Davidoff et al., 1985b; Morris et al., 1986; Davidoff et al., 1987; Richards et al., 1988), chronic alcohol or substance abuse (Heinemann et al., 1988), premorbid learning disability, use of psychoactive medication, or motivational problems. Although some of the effects of these disorders may be transient (Richards et al. 1988), many of the problems in understanding and mental processing may persist during or beyond the first few months following injury.

Recognition of the presence and nature of these deficits during this initial phase of the post-injury course of recovery is important because this is the time period during which maximal rehabilitation takes place. Rehabilitation of the SCI patient is an intensive process that includes training in personal care, mobility, and community skills and the facilitation of physical and psychosocial adaptation to the disability; any impediment to learning and adjustment that these cognitive problems may pose might compromise the achievement of optimal rehabilitation outcomes.

A number of prospective and retrospective studies have examined the problem of cognitive dysfunction in SCI patients from a variety of perspectives. Early studies (Silver et al., 1980-81; Schueneman and Morris, 1982; Dubo and Delaney, 1984; Wagner et al., 1984; Davidoff et al., 1985a; Wilmot, 1985) focused on the coincidence of closed head injury with SCI. However, more recent reports (Wilmot et al., 1985; Davidoff et al., 1985b) have underscored the potential impact of other causes of cognitive dysfunction, thereby broadening the scope of investigations to include neuropsychological deficits resulting from a variety of aetiologies. Regardless of the cause, the end result of these insults to the brain are potentially deleterious to the rehabilitation process, and possibly are remediable if recognised early. These problems often can be identified and their severity assessed by the use of neuropsychological evaluations. 
Several investigators have reported the magnitude and nature of neuropsychological test abnormalities among SCI patients using a broad range of assessments of cognitive function (Wilmot et al., 1985; Davidoff et al., 1985b; Richards et al., 1988). Unfortunately, applicability of the findings from many of these studies has been hampered by at least two major methodological flaws: the administration of neuropsychological tests which are limited in scope and sensitivity, and the failure to compare the frequency and severity of cognitive impairment among SCI patients with those of concurrent control subjects.

The present investigation was a collaborative study which was designed to:

1. Determine the nature, pattern, and extent of cognitive deficits in a group of acute SCI patients, using a comprehensive battery of reliable and validated neuropsychological assessments to study a broad range of cognitive functions.

2. Compare these findings with those seen in a concurrent control group matched for age, gender, educational level, and geographic location.

\section{Methods}

\section{Patients}

The study sample consisted of individuals aged 18 to 55 years, admitted for initial care and rehabilitation following an acute traumatic SCI to one of two regional model spinal cord injury care programmes. The patients were studied at the University of Michigan Medical Center Acute Interdisciplinary Spinal Cord Injury Programme, Ann Arbor, Michigan and the South Eastern Michigan Spinal Cord Injury System, Rehabilitation Institute, Detroit, Michigan. All patients had completed a high school education or its equivalent (GED). Patients with a recent history (less than 6 months prior to SCI) of mild closed head injury (CHI) (defined by Rimel et al., 1981), and patients who had any history of moderate or severe CHI (Rimel et al., 1982), were excluded from the study in order to avoid the potential confounding effects of these factors on the findings. Informed consent was obtained from all patients, and the study protocol was approved by the Institutional Review Board at each study site.

\section{Control subjects}

The control group consisted of paid volunteers at each study site. Controls were chosen to match as closely as possible the SCI patient group means or frequency distributions for age, gender, educational level and geographic location since these factors have been reported to influence neuropsychological test performance (Prigatano and Parsons, 1976; McGlone, 1978; Lezak, 1983; Bornstein and Matazzaro, 1985; Levin et al., 1987; Sundet 1988). Controls with any history of $\mathrm{CHI}$ or recent high frequency alcohol or substance abuse were excluded from this investigation. The control group was generated in such a way so as to optimise the likelihood of obtaining favourable test results, as a means of having an ideal measure against which scores of spinal cord injured patients could be compared. All control subjects provided informed written consent. 


\section{Procedure}

Demographic and injury characteristics. Demographic information, including age, gender, and years of education, was collected from each patient and control subject. Each patient was questioned regarding a history of high frequency alcohol and/or substance abuse (Heinemann et al., 1988). Occurrence of acute closed head injury, defined by any interval of post-traumatic amnesia (Levin et al., 1979; Davidoff et al., 1988) at the time of SCI, was recorded. Information concerning alcohol and/or substance abuse and CHI was elicited from patients because of the impact which these factors may have on cognitive performance (Russell, 1932; Russell and Nathan, 1946; Russell and Smith, 1961; Steadman and Graham, 1970; Russell, 1971; Brooks, 1972; Grant et al., 1984; Hillbom and Holm, 1986). Level and aetiology of SCI also were documented for each patient.

Neuropsychological assessment. A comprehensive motor-free battery of neuropsychological assessments that were considered reliable and reproducible measures of attention, concentration, memory, abstract reasoning, and problem-solving ability was given to all patients and control subjects. The SCI patient group presented unique challenges in the design of the neuropsychological test battery. Unlike most studies of cognitive impairment, it was not feasible to rely on paper and pencil neuropsychological tests due to the loss of integrity of upper extremity motor and sensory function in many of the patients in this study. Additionally, the test protocol required adequate flexibility in its administration in order to allow patients the opportunity to perform pressure relief activities, bladder and bowel care, and positional adjustments. These factors necessitated the use of a motor-free battery with administration of testing over several brief sessions. The total time required to complete the battery employed in this investigation was less than 3 hours for the co-operative, motivated patient. The test battery was administered an average ( \pm standard error) of $71.5 \pm 3.5$ days (range 23-177 days) post-injury, and included:

1. Halstead Category Test, Booklet Form (HCT) (Reitan, 1979).

2. Vocabulary Subtest of the Wechsler Adult Intelligence Scale-Revised (VOCAB) (Lezak, 1983).

3. Mental Control Subtest (MC) of the Wechsler Memory Scale (WMS) (Wechsler, 1945).

4. Logical Memory (LM) and Paired Associates (PA) Subtests of the WMSRussell Adaptation, each with Initial (INIT) and 30-minute Recall (RECALL) trials (Wechsler, 1945; Russell, 1975).

5. Rey Auditory Verbal Learning Test (RAVLT) (Lezak, 1983).

Each test was selected for a specific reason.

The HCT was chosen because it reliably evaluates deficits in attention, concentration, visual problem-solving ability, abstract reasoning, ability to make constructive use of feedback (DeWolfe et al., 1971; Lansdell and Donnelly, 1977; Boll, 1981; Pendleton and Heaton, 1982; Lynch, 1983), and ability to adapt to new situations (Rothke, 1986). The HCT has been reported to be nearly as sensitive an indicator of cognitive dysfunction as all of the other tests 
in the Halstead-Reitan Neuropsychological Battery combined (Reitan, 1955; Fitzhugh et al., 1961; Shaw, 1966). The Booklet Form of the HCT is less cumbersome to administer than the standard format, and has similar levels of reliability and validity (Defillipis, 1979; Kimura, 1981).

The VOCAB was given to assess verbal and general mental ability (Lezak, 1983). The MC tests automatic and simple conceptual tracking (Lezak, 1983). The LM evaluates immediate recall of verbal ideas from two written paragraphs (Lezak, 1983). The PA tests verbal retention from associated and non-associated word pairs (Lezak, 1983). The 30-minute Recall trials of the LM and PA Subtests of the WMS provide assessments of long-term verbal and non-verbal storage capacity (Russell, 1975). Per cent retention of stored information was calculated for the LM (PCT-LM) and PA (PCT-PA) by:

$$
\frac{\text { Score, recall trial }}{\text { Score, initial trial }}(\times 100)
$$

The RAVLT was given to measure immediate memory span and retention following an interpolated activity (Lezak, 1983). This test has 8 trials (I, II, III, IV, V, Interference (B), VI, and Recognition).

\section{Data analysis}

Descriptive statistics were used to characterise the sample. Age and number of years of education were compared between patients and controls using Student's t-test; gender and geographic distribution were compared with Chi-square analysis.

Values for the mean and standard error for each of the neuropsychological assessments were obtained from SCI patients and control subjects, and compared using Student's t-test.

In a separate analysis, frequencies of neuropsychological abnormality were determined. First, values for the mean and standard deviation were obtained from scores among control subjects for each of the tests. Then, a level of 'impairment' was calculated for each test based on a score that exceeded the limit for 'normal' performance, defined as two standard deviations (one-tailed) from the control mean. Based on this criterion, the prevalence (percentange) of patients with impaired test performance on each of the neuropsychological tests was determined for patients and for control subjects. A one-tailed analysis was conducted because the focus of the study was on a comparison of the proportions of patients with inferior or impaired performance only.

\section{Results}

\section{Sample description}

Characteristics of the 81 SCI patients and 61 control subjects are shown in Table I, which also demonstrates that there were no significant differences between patient and control groups with respect to age, gender, educational level, or geographic location. Thirty five of the spinal cord injuries were at the cervical level, 34 were at the thoracic level, and 12 were at the lumbosacral 
Table I Demographic characteristics

\begin{tabular}{lccc}
\hline & Controls & Patients & Statistic \\
\hline Sample size & 61 & 81 & \\
Age (years, mean $\pm 1 \mathrm{se})$ & $27 \cdot 5 \pm 1 \cdot 0$ & $29 \cdot 7 \pm 1 \cdot 0$ & $\mathrm{t}(140)=1 \cdot 58 ; \mathrm{p}=\mathrm{NS}$ \\
Gender: male & $45(74 \%)$ & $64(79 \%)$ & $X^{2}(1)=0 \cdot 54 ; \mathrm{p}=\mathrm{NS}$ \\
$\quad$ female & $16(26 \%)$ & $17(21 \%)$ & $\mathrm{t}(140)=1 \cdot 14 ; \mathrm{p}=\mathrm{NS}$ \\
Education (years, mean $\pm 1 \mathrm{se})$ & $12 \cdot 8 \pm 0 \cdot 2$ & $13 \cdot 1 \pm 0 \cdot 2$ & $X^{2}(1)=3 \cdot 50 ; \mathrm{p}=\mathrm{NS}$ \\
Geographic location: Detroit & $39(64 \%)$ & $39(48 \%)$ & \\
$\quad$ Ann Arbor & $22(36 \%)$ & $42(52 \%)$ & \\
\hline
\end{tabular}

Table II Neuropsychological test scores for patients and controls

\begin{tabular}{|c|c|c|c|}
\hline Test & Controls & Patients & Statistic \\
\hline$\overline{\mathrm{HCT}}$ & $45 \cdot 0 \pm 3 \cdot 4$ & $57 \cdot 3 \pm 3 \cdot 4$ & $\mathrm{t}(132)=-2.51 ; \mathrm{p}<0.01$ \\
\hline VOCAB & $49 \cdot 5 \pm 1 \cdot 3$ & $41.9 \pm 1.5$ & $\mathrm{t}(134)=4.20 ; \mathrm{p}<0.005$ \\
\hline MC & $7 \cdot 9 \pm 0 \cdot 2$ & $7 \cdot 1 \pm 0 \cdot 2$ & $\mathrm{t}(139)=2.70 ; \mathrm{p}<0.005$ \\
\hline LM-INIT & $11 \cdot 2 \pm 0.4$ & $9 \cdot 6 \pm 0.4$ & $\mathrm{t}(139)=2.77 ; \mathrm{p}<0.005$ \\
\hline LM-RECALL & $6 \cdot 1 \pm 0 \cdot 1$ & $5 \cdot 0 \pm 0 \cdot 2$ & $\mathrm{t}(130)=4.73 ; \mathrm{p}<0.005$ \\
\hline PCT-LM & $84.4 \pm 1 \cdot 5$ & $81 \cdot 6 \pm 3 \cdot 0$ & $\mathrm{t}(122)=0.85 ; \mathrm{p}=\mathrm{NS}$ \\
\hline PA-INIT & $11 \cdot 1 \pm 0 \cdot 3$ & $9 \cdot 6 \pm 0.3$ & $\mathrm{t}(135)=3.42 ; \mathrm{p}<0.005$ \\
\hline PA-RECALL & $6 \cdot 1 \pm 0 \cdot 1$ & $5 \cdot 0 \pm 0 \cdot 2$ & $t(130)=4.73 ; p<0.005$ \\
\hline PCT-PA & $55 \cdot 2 \pm 1 \cdot 2$ & $53 \cdot 7 \pm 1 \cdot 4$ & $\mathrm{t}(130)=0 \cdot 79 ; \mathrm{p}=\mathrm{NS}$ \\
\hline RAVLT-I & $7 \cdot 4 \pm 0.2$ & $6 \cdot 6 \pm 0.2$ & $\mathrm{t}(137)=2.20 ; \mathrm{p}<0.01$ \\
\hline RAVLT-II & $10.4 \pm 0.3$ & $9 \cdot 0 \pm 0.3$ & $\mathrm{t}(138)=3.28 ; \mathrm{p}<0.005$ \\
\hline RAVLT-III & $11.9 \pm 0.3$ & $10 \cdot 5 \pm 0.3$ & $\mathrm{t}(138)=3.77 ; \mathrm{p}<0.005$ \\
\hline RAVLT-IV & $12 \cdot 8+0 \cdot 2$ & $11 \cdot 6 \pm 0.3$ & $\mathrm{t}(137)=3.19 ; \mathrm{p}<0.005$ \\
\hline RAVLT-V & $13 \cdot 7 \pm 0 \cdot 2$ & $12 \cdot 3 \pm 0 \cdot 3$ & $\mathrm{t}(137)=4.01 ; \mathrm{p}<0.005$ \\
\hline RAVLT-B & $6 \cdot 7 \pm 0 \cdot 3$ & $6 \cdot 5 \pm 0.9$ & $t(137)=0 \cdot 19 ; p=N S$ \\
\hline RAVLT-VI & $12.4 \pm 0.3$ & $10 \cdot 7 \pm 0.3$ & $\mathrm{t}(136)=3.94 ; \mathrm{p}<0.005$ \\
\hline REY-RECOG & $14 \cdot 0 \pm 0.2$ & $13 \cdot 0 \pm 0.3$ & $\mathrm{t}(132)=3.07 ; \mathrm{p}<0.005$ \\
\hline
\end{tabular}

All values for test scores given as mean \pm standard error

level. Injuries were caused by road traffic addidents $(n=42)$, gunshot wounds $(\mathrm{n}=11)$, other assaults $(\mathrm{n}=16)$, falls $(\mathrm{n}=7)$, sporting incidents $(\mathrm{n}=3)$ and other causes $(n=2)$. Twenty six patients $(32 \%)$ had a recent history of high frequency alcohol and/or substance abuse. Acute concurrent closed head injury, as defined by any interval of post-traumatic amnesia (PTA) at the time of SCI, occurred in 35 patients $(44 \%)$. Of these patients, 20 had PTA for less than 1 hour, 9 had PTA for 1 to 24 hours, 3 had PTA between 1 day and 1 week, and 3 had more than 1 week of PTA.

\section{Neuropsychological test results}

The means and one standard error confidence intervals of scores on each neuropsychological assessment are shown in Table II. Performance levels of SCI patients were significantly more impaired than those of control subjects for the HCT, VOCAB, MC, LM-INIT, LM-RECALL, PA-INIT, PA-RECALL, RAVLT-I, RAVLT-II, RAVLT-III, RAVLT-IV, RAVLT-V, RAVLT-VI, and REY-RECOG. The PCT-LM, PCT-PA, and RAVLT-Interference trial (RAVLT-B) were the only tests on which no statistically significant differences were detected between scores of SCI patients and those of control subjects.

The prevalance of abnormal neuropsychological test performance for each of the assessments is shown for SCI patients and controls in the Figure. Impaired 


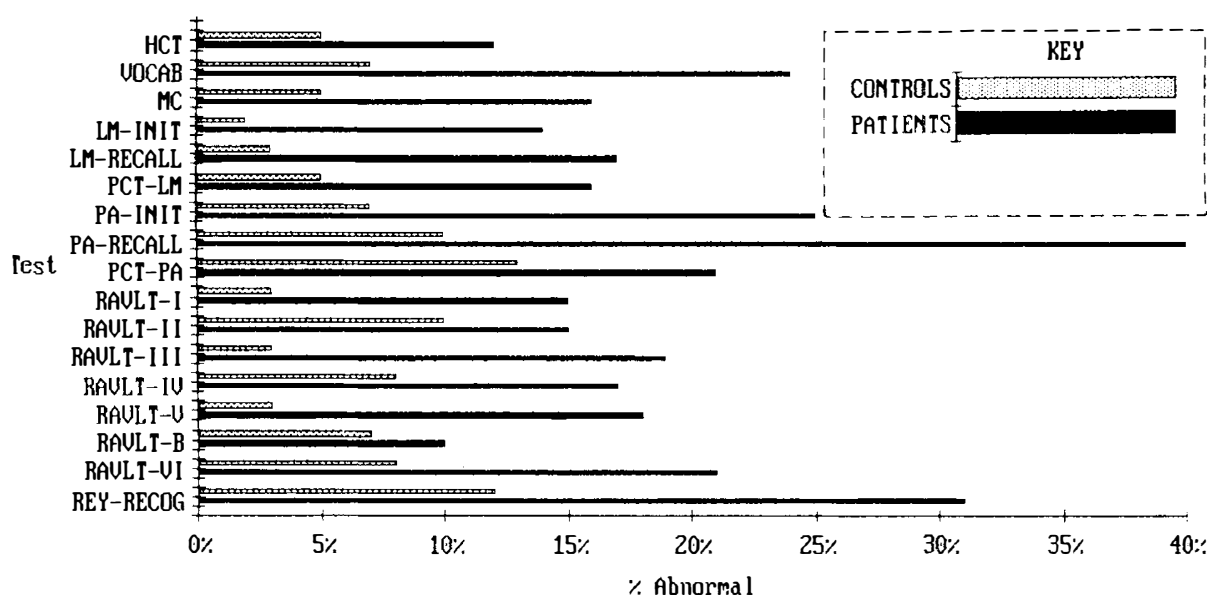

Figure Prevalance of neuropsychological test abnormalities for SCI patients and control subjects.

performance was noted most frequently on the PA-RECALL (40\%), REYRECOG $(31 \%)$, and VOCAB $(24 \%)$, and least frequently on the RAVLT-B $(10 \%)$ and HCT $(12 \%)$.

\section{Discussion}

Rehabilitation after SCI involves the acquisition of new skills and knowledge (Bleiberg and Merbitz, 1983). This process requires the ability to attend to, concentrate on, understand, process, retain, retrieve, integrate, and utilise information. Achievement of the goals of rehabilitation, which include maximal independence in self-care and mobility skill performance, prevention of medical complications, optimal emotional adjustment to the disability, and complete reintegration into the community after hospitalisation, may be adversely affected by inability to learn or effectively apply the knowledge and skills which are taught during inpatient rehabilitation.

In this context, it is significant that the prevalence of neuropsychological abnormality on the tests ranged between $10 \%$ and $40 \%$. It also is important to note that patients demonstrated substantially more impaired performance than did control subjects on most of the measures, despite similarities in age, gender, educational level, and geographic location. This may have been related, in part, to the high frequencies of acute CHI $(44 \%)$ and alcohol or substance abuse $(32 \%)$ among SCI patients. Similar prevalences for CHI (Silver et al., 1980; Schueneman and Morris, 1982; Dubo and Delaney, 1984; Wgner et al., 1984; Davidoff et al., 1985) and alcohol abuse (Heinemann et al., 1988) have been reported previously. It was not within the scope of the present investigation to examine specifically the potential influence of such factors as age, gender, education, level of injury, presence of closed head injury, depression, or alcohol/ substance abuse on neuropsychological performance. However, the impact of many of these factors on cognitive functioning is well known (Russell, 1932; Russell and Nathan, 1946; Russell and Smith, 1961; Steadman and Graham, 1970; Russell, 1971; Brooks, 1972; Grant et al., 1984; Hillbom and Holm, 1986). 
Other studies on the co-existence of cognitive dysfunction in SCI patients have yielded results which are similar to those found in the present investigation. Wilmot and associates (1985) noted a prevalence rate of cognitive impairment of $64 \%$ in a study of 67 SCI patients at 'high risk' for head trauma, based on the presence of any one of four inclusionary criteria (tetraplegia associated with deceleration impact, history of documented loss of consciousness, presence of neurological indicators, or need for respiratory support), using a battery of 11 tests. Richards et al. (1988) recently reported that some of the cognitive deficits that were found on a standard neuropsychological test battery shortly after onset of SCI persisted for nearly 1 years following injury while patients recovered from other deficits. In particular, certain measures of attention, vocabulary, and memory improved over time.

Davidoff et al. (1985) administered the Halstead Category Test between 8 and 12 weeks after injury to 30 consecutive acute SCI patients and found that $57 \%$ demonstrated impaired performance, defined as greater than or equal to 51 errors. SCI patients with a concurrent or pre-morbid CHI were slightly more likely to have abnormal scores than were SCI patients without a history of $\mathrm{CHI}$.

Although these reports have provided the basis for the more comprehensive assessment conducted in the present investigation, a major design flaw in all of the studies to date has been a lack of concurrent controls matched for sociodemographic factors. It is extremely important to consider these factors, including age, gender, education, and geographic location, as they have been found to influence neuropsychological performance (Prigatano and Parsons, 1976; Lezak, 1983; Levin et al., 1987). The present study was designed to address the issue of comparison with controls.

The tests which were used in the research protocol were selected to reflect a broad range of cognitive abilities, including attention, concentration, verbal short term memory storage and retrieval, problem-solving, and abstract reasoning. The patients showed relatively high rates of abnormality in most of these areas, suggesting diffuse impairment in cognitive functioning. However, concentration and initial learning (e.g. MC, LM-INIT, PA-INIT, RAVLT I-VI, REY-RECOG) appeared to have been particularly impaired, while the relative amount of verbal and non-verbal material retained at 30-minute recall was preserved (PCT-LM, PCT-RA). As previously reported (Davidoff et al., 1985; Richards et al., 1988), HCT performance was severely impaired, indicative of compromise of the ability to adapt to new situations and to shift to new mental sets. The depressed VOCAB performance among the patients, given that many of the sociodemographic factors were controlled for, may represent difficulties experienced with word retrieval and syntactic use. A common style of learning, and therefore an optimal strategy for training, may be suggested by these data.

The findings of this study have major implications for the design and implementation of SCI rehabilitation programmes. Accurate descriptions of specific neuropsychological deficits in individual patients provides the opportunity for modification of each patient's treatment programme and directs the therapeutic approach. For example, a patient with impaired verbal retention may learn better by using a graphic representation of a functional task. The observation in this study that initial adaptation and learning is impaired but that retention 
of information committed to long term memory is relatively preserved suggests that patients may perform their skills better if the tasks are 'overlearned' or practiced repeatedly. Therapeutic modifications such as these might assist clinicians in developing appropriate and effective teaching strategies which better focus the rehabilitation efforts toward addressing specific patient needs, thereby enhancing the likelihood of achieving favourable rehabilitation outcomes.

\section{Acknowledgements}

This study was funded by a Clinical Investigator Development Award (GD) from the National Institute of Neurological and Communicative Disorders and Stroke, National Institute of Health, Bethesda, MD (NS-01120-03), and by grants from the Kenny Michigan Rehabilitation Foundation, Southfield, MI, and the Spinal Cord Research Foundation of the Paralyzed Veterans of America, (PR-529) Washington, DC. Secretarial assistance was provided by Jean Voeks, Patricia Wagner, Susan P. Moreau and Denise D. Dyson.

\section{References}

Bleiberg J, Merbitz D 1983 Learning goals during initial rehabilitation hospitalization. Archives of Physical Medicine and Rehabilitation 64:448-450.

Boll TJ 1981 The Halstead-Reitan, Neuropsychological Battery. In: Filskov SB, Boll TJ (eds) Handbook of Clinical Neuropsychology. Wiley-Intersciences, New York.

Bornstein RA, MATARAZzo JD 1985 Wechsler VIQ versus PIQ differences in cerebral dysfunction: A literature review with emphasis on sex differences. Fournal of Clinical Neuropsychology 4:319-334.

Brooks DN 1972 Memory and head injury. Fournal of Nervous and Mental Diseases 155:350-355.

DAvidoff G, MORRIS J, Roth E, et al. 1985 Closed head injury in spinal cord injured patients: Retrospective study of loss of consciousness and post-traumatic amnesia. Archives of Physical Medicine and Rehabilitation 66:41-43.

Davidoff G, Morris J, Roth E, et al. 1985 Cognitive dysfunction and mild closed head injury in traumatic spinal cord injury. Archives of Physical Medicine and Rehabilitation 66:489-491.

Davidoff G, Johnson M, Thomas P, et al. 1986 Utility of the Galveston orientation and amnesia test in the determination of closed head injury in acute spinal cord injury patients. Archives of Physical Medicine and Rehabilitation 69:432-434.

Davidoff G, Roth E, Thomas P, et al. 1987 Three center study of risk factors for cognitive impairment in acute spinal cord injury patients. Archives of Physical Medicine and Rehabilitation 68:673-674.

Defillipis NA, McCampbell E, Rogert P 1979 Development of a booklet form of the Category Test: Normative and validity date. Fournal of Clinical Neuropsychology 1:339-342.

DeWolfe AS, BARRell RP, BECKer BC, SPANCER FE 1971 Intellectual deficit in chronic schizophrenia and brain damage. Fournal of Consulting Clinical Psychology 36:197-204.

Dubo H, Delaney G 1984101 Spinal cord injuries due to motor vehicle accidents. Proceedings of the American Spinal Injury Association Annual Meeting, pp 35-38.

Fitzhugh KB, Fitzhugh LC, Reitan RM 1961 Psychological deficits in relation to acuteness of brain dysfunction. Fournal of Consulting and Clinical Psychology 25:61-66.

Grant I, AdAMs K, REed R 1984 Aging, abstinence, and medical risk factors in the prediction of neuropsychologic deficit among long-term alcoholics. Archives of General Psychiatry 41: 710-718.

Heinemann A, Donohue R, KEEN M, et al. 1988 Alcohol use by persons with recent spinal cord injuries. Archives of Physical Medicine and Rehabilitation 69:619-624.

Hillbom, M, Holm L 1986 Contribution of traumatic head injury to neuropsychological deficits in alcoholics. Fournal of Neurological and Neurosurgical Psychiatry 49:1348-1353.

KimURA S 1981 Card form of the Reitan modified Halstead Category Test. Fournal of Consulting and Clinical Psychology 49:145-146.

LANSDEll H, DonNelly EF 1977 Factor analysis of the Wechsler Adult Intelligence Scale Subtests and the Halstead-Reitan Category and Tapping tests. Fournal of Consulting and Clinical Psychology 45:412-416. 
LEVIN HS, MATtis S, RUFF RM, et al. 1987 Neurobehavioral outcome following minor head injury: a three-center study. Fournal of Neurosurgery 66:234-243.

Levin HS, O'Donnell VA, Grossman RG 1979 The Galveston orientation and amnesia test. A practical scale to assess cognition after head injury. Fournal of Nervous and Mental Diseases 167:675-684.

LEZAK MD 1983 Neuropsychological Assessment. Oxford Univ. Press, New York.

LYNCH W 1983 Neuropsychological assessment. In: Rosenthal M, Griffith ER, Bond MR, Miller JD (eds): Rehabilitation of the Head Injured Adult. F. A. Davis, Philadelphia, pp 292-294.

MCGLONE J 1978 Sex differences in functional brain asymmetry. Cortex 14:122-128.

Morris J, Roth E, DAvidoff G 1986 Mild closed head injury and cognitive deficits in spinal cord injured patients: Incidence and impact. Fournal of Head Trauma Rehabilitation 2:31-42.

Pendleton MG, Heaton RK 1982 A comparison of the Wisconsin Card Sorting Test and the Category Test. Fournal of Clinical Psychology 38:392-396.

Prigatano GP, Parons OA 1976 Relationship of age and education to Halstead test performance in different patient populations. Fournal of Consulting and Clinical Psychology 44:527-533.

REITAN RM 1979 Manual for administration of neuropsychological test batteries for adults and children. Privately published by the author, Tucson.

REITAN RM 1955 Investigation of validity of Halstead's measure of intelligence. Archives of Neurology and Psychiatry 73:28-35.

RICHARDS JS, BROWN L, HAGGLUND K, et al. 1988 Spinal cord injury and concomitant traumatic brain injury: Results of a longitudinal investigation. American fournal of Physical Medicine and Rehabilitation 67:211-216.

Rimel RW, GIORDANi B, BARTh JT, et al. 1981 Disability caused by minor head injury. Neurosurgery 9:221-228.

Rimel RW, GioRdani B, BARTh JT, JANe JA 1982 Moderate head injury: Completing the clinical spectrum of brain trauma. Neurosurgery 11:344-351.

RothKe S 1986 The role of set shifting cues on the Wisconsin Card Sorting Test and Halstead Category Test. International fournal of Clinical Neuropsychology 8::11-14.

RUSSELL EW 1975 A multiple scoring method of the assessment of complex memory function. fournal of Consulting and Clinical Psychology 43:880-889.

RUSSELL WR 1932 Cerebral involvement in head injury. Brain 55:549-603.

RuSSELl WR, Nathan PQ 1946 Traumatic amnesia. Brain 69:280-300.

Russell WR, SMith A 1961 Post-traumatic amnesia in closed head injury. Archives of Neurology 5:4-17.

RUSSELL WR 1971 The Traumatic Amnesias. Oxford University Press, London.

SCHUENEMAN AL, MORRIS J 1982 Neuropsychological deficits associated with spinal cord injury. Spinal Cord Injury Digest 4:35, 64.

SHAw DJ 1966 The reliability and validity of the Halstead Category Test. Fournal of Clinical Psychology 22:176-179.

Silver JR, MORRIS WR, OtFINOWSKI JS 1980-1981 Associated injuries in patients with spinal injury. Injury 12:219-224.

Steadman JH, Graham JG 1970 Rehabilitation of the brain injured. Proceedings of the Royal Society of Medicine 63:23-28.

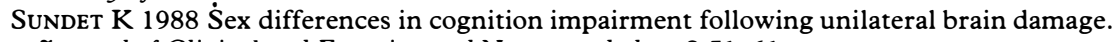
Fournal of Clinical and Experimental Neuropsychology 8:51-61.

WAGNer KA, KopankiY DR, Esposito L 1984 Combined head and spinal cord injury: Potential for errors in diagnosis and treatment. Proceedings of the American Spinal Injury Association Tenth Annual Scientific Meeting, pp 96-104.

Wilmot CB, Cope DN, Hall KM, ACKer M 1985. Occult head injury: Its incidence in spinal cord injury. Archives of Physical Medicine and Rehabilitation 66:227-231. 